\title{
Synthesis of highly dispersed Pt nanoparticles into carbon supports by fluidized bed reactor atomic layer deposition to boost PEMFC performance
}

\author{
Woo-Jae Lee', Susanta Bera', Chang Min Kim', Eun-Kyong Koh', Woong-Pyo Hong², Seung-Jeong Oh²,
} EunAe Cho ${ }^{3}$ and Se-Hun Kwon (i)

\begin{abstract}
The performance of proton exchange membrane fuel cells (PEMFCs) depends on the controlled size, dispersion and density of Pt nanoparticles (NPs) on carbon supports, which are strongly affected by the carbon characteristics and fabrication methods. Here, we demonstrated a high-performance Pt/carbon catalyst for PEMFCs using fluidized bed reactor atomic layer deposition (FBR-ALD) that was realized by an effective matching of the carbon supports for the FBR-ALD process and an optimization of the ionomer content during the preparation of the membrane electrode assembly (MEA). For this, the synthesis of Pt NPs was conducted on two porous supports (Vulcan XC-72R and functionalized carbon) by FBR-ALD. The functionalized carbon possessed a higher surface area with a large pore volume, abundant defects in a disordered structure and a large number of oxygen functional groups compared to those of the well-known Vulcan carbon. The favorable surface characteristics of the functionalized carbon for nucleation produced Pt particles with an increased uniformity and density and a narrow size range, which led to a higher electrochemical surface area (ECSA) than that of Pt/Nulcan carbon and commercial Pt/carbon. The PEMFC test of the respective Pt/carbon samples was investigated, and highly dense and uniform Pt/functionalized-carbon showed the highest performance through optimization of the higher ionomer content compared to that for the ALD Pt growth on Vulcan carbon and commercial Pt/carbon. In addition, the Pt catalyst using ALD demonstrated a significant long-term stability for the PEMFC. This finding demonstrates the remarkable advantages of FBR-ALD for the fabrication of Pt/carbon and the ability of functionalized carbon supports to achieve a high PEMFC efficiency and an enhanced durability.
\end{abstract}

\section{Introduction}

To mitigate the use of fossil fuel-derived energy for transportation, proton exchange membrane fuel cells (PEMFCs) are one of the most promising and attractive power sources ${ }^{1-3}$. Pt is an outstanding active material for catalysts in PEMFC stacks, but its successful commercialization is lagging due to its high $\operatorname{cost}^{4}$. To make the

Correspondence: Se-Hun Kwon (sehun@pusan.ac.kr)

${ }^{1}$ School of Materials Science and Engineering, Pusan National University, 30 Jangjeon-Dong Geumjeong-Gu, Busan 46241, Republic of Korea

${ }^{2}$ Materials Development Center, Hyundai Motor Company, 37

Cheoldobangmulgwan-ro, Uiwang-si, Gyeonggi-do 16082, Republic of Korea

Full list of author information is available at the end of the article technology economically viable, a reduction in the $\mathrm{Pt}$ loading ${ }^{5}$ and an increase in the efficient Pt surface area should be established simultaneously to obtain an excellent PEMFC activity and stability ${ }^{6-8}$. In addition, an improvement in the fuel cell efficiency has been associated with the optimized three-phase interface that is composed of an ion-conducting electrolyte (ionomer) next to a solid catalyst surface ${ }^{9-12}$. After reacting $\mathrm{H}_{2}$ gas molecules in the solid phase of the anode, the protons meet in the electrolyte phase and then react with $\mathrm{O}_{2}$ in the solid-electrolyte interface, producing water as a byproduct ${ }^{13}$. To enhance the efficiency of the three-phase interface, protons in the three-dimensional network of the

\section{() The Author(s) 2020}

(c) (i) Open Access This article is licensed under a Creative Commons Attribution 4.0 International License, which permits use, sharing, adaptation, distribution and reproduction cc) in any medium or format, as long as you give appropriate credit to the original author(s) and the source, provide a link to the Creative Commons license, and indicate if changes were made. The images or other third party material in this article are included in the article's Creative Commons license, unless indicated otherwise in a credit line to the material. If material is not included in the article's Creative Commons license and your intended use is not permitted by statutory regulation or exceeds the permitted use, you will need to obtain permission directly from the copyright holder. To view a copy of this license, visit http://creativecommons.org/licenses/by/4.0/. 
fuel cell should be easily accessible to every portion of the cell by optimizing the ionomer content.

For PEMFCs, a Pt catalyst (Pt/carbon black) provides a large surface area and large accessible pores for hydrogen and oxygen molecules to contact the Pt surface ${ }^{14,15}$. However, it is not easy to uniformly deposit Pt nanoparticles (NPs) in porous carbon supports because the textural properties (surface area, porosity, and pore volume), structural defects and functional groups on the carbon surface strongly affect the growth mechanism during Pt deposition ${ }^{13,16}$. These characteristics of the carbon can act as strong binding sites to anchor the $\mathrm{Pt}$ $\mathrm{NPs}^{17}$. Porous carbon with an internal porosity can offer a high surface area for a large number of Pt NPs compared to solid carbons, e.g., acetylene black and graphitized carbons ${ }^{18}$. The defect structures of the carbon can play an important role in controlling the Pt deposition density due to their enhanced chemical reactivity compared to that of an inert carbon lattice ${ }^{17,19}$. In addition, during the deposition process, a large number of functional groups on the carbon surface can promote the nucleation of $\mathrm{Pt}$ NPs and hinder NP agglomeration, resulting in a reduction in the Pt NP size and a narrow size dispersion, which can improve the degradation characteristics ${ }^{20-22}$. Therefore, it is demonstrated that a carbon support with favorable textural properties, optimized structural surface defects and oxygen functional groups should be considered for Pt NP deposition to fabricate efficient Pt/ carbon catalysts for PEMFCs.

To synthesize Pt/carbon, several wet-chemical ${ }^{23,24}$, and gas-phase processes ${ }^{25,26}$ have been extensively studied. However, most of the processes involve complicated steps and produce a wide range of Pt NP size distributions with high Pt loading and low productivity rates, which demonstrate poor long-term durability. Compared to these methods ${ }^{27,28}$, atomic layer deposition (ALD) can have many unique inherent merits for preparing Pt NPs on porous carbon supports. It allows the vapors of the precursor to penetrate into deep regions of the porous carbon support for uniform deposition of Pt NPs, which can lead to precise control of the size of the NPs within the porous matrix to improve the electrochemical surface area (ECSA) with a low Pt loading ${ }^{29-31}$. To date, most of the studies using ALD have focused on thin film-based depositions, such as carbon paper, carbon on glassy carbon and carbon cloth $^{29,31-33}$. To fabricate powder coatings on a large scale, several modified ALD systems, such as static and rotary reactor methods, have been studied, and have synthesized diverse NP materials on porous materials ${ }^{34-36}$. Among them, to synthesize the Pt/carbon catalyst for commercialization of PEMFCs, a fluidized bed reactor (FBR) ALD is an excellent modified ALD system due to its excellent gas transfer, uniform NPs and large production quantity ${ }^{37,38}$. However, in light of a few reported FBR-ALD studies ${ }^{21,38}$, the synthesis of a FBR Pt catalyst through a process with increased efficiency and speed, and an improved fluidizing behavior is highly desired. In addition, the growth behavior of the ALD process also strongly depends on the surface conditions ${ }^{39-41}$, which can affect the uniformity, particle size and density of the Pt NPs toward improving the electrochemical surface active area (ECSA) and durability. However, the effect of the carbon support on Pt formation based on wet processing has been intensely studied despite the different growth mechanisms between the wet process and $\mathrm{ALD}^{14,19}$. Therefore, it is crucial for the ALD process to produce these favorable characteristics of carbon black to control the size, density and distribution of uniform Pt NPs to improve the PEMFC activity, reduce the Pt loading, and commercialize the production of FBRALD Pt/carbon catalysts.

Herein, therefore, we report a very efficient, fast and scalable FBR-ALD process for a highly uniform Pt catalyst on two well-known porous carbons, Vulcan and Vinatech. The effect of the carbon supports on tuning the deposited Pt NP size and density was systematically investigated. The textural properties (surface area, mesoporosity and pore volume), oxygen functional groups and structural defects of the carbon supports can influence the Pt NP deposition characteristics, uniformity and density of the NPs in the ALD process. Based on a comprehensive study of FBR-Pt/carbon catalysts, electrochemical properties and a test of the fuel cell activity were implemented, and uniformly dispersed and highly dense Pt NPs produced using FBR-ALD with an optimized ionomer content showed efficient fuel cell performance with excellent stability.

\section{Materials and methods}

\section{Fabrication of the Pt catalyst using the FBR-ALD process}

The synthesis of Pt particles on carbon supports was achieved by using an FBR-ALD system. The two carbon supports, Vulcan XC-72 R and functionalized carbon (VFC-SP0450), are referred to as Vulcan and Vinatech, respectively. After citric acid treatment, a controlled cluster size $(60-120 \mu \mathrm{m})$ of the carbons $(0.4 \mathrm{~g})$ was inserted in the chamber to thoroughly fluidize them (see supporting information for a more detailed synthesis process of the Pt catalyst). The base and working pressures were kept at 0.01 Torr and 0.4 Torr, respectively. The reactor was heated to $300^{\circ} \mathrm{C}$, and a gas line was maintained at $100^{\circ} \mathrm{C}$. The Pt precursor and reactant were $\mathrm{MeCpPtMe}_{3}$ (trimethyl (methyl cyclopentadienyl) platinum (IV), i-Chem Co.) at $30^{\circ} \mathrm{C}$ and UHP (ultra-high purity) $\mathrm{O}_{2}$ gas, respectively. Before the first cycle, the preprocessing was performed with Ar gas at $50 \mathrm{sccm}$ $(30 \mathrm{~s})$ and then at $100 \mathrm{sccm}(60 \mathrm{~s})$ to prevent abrupt fluidizing of the powder. During the process, UHP Ar gas 
at $100 \mathrm{sccm}$ was continuously supplied into the reactor for constant $\mathrm{MeCpPtMe}_{3}$ precursor bubbling, purging and fluidizing of the powder. One cycle consisted of a $\mathrm{MeCpPtMe}_{3}$ pulse $(120 \mathrm{~s})$, purge $(90 \mathrm{~s}), \mathrm{O}_{2}$ pulse with $30 \mathrm{sccm}(90 \mathrm{~s})$ and then another purge $(90 \mathrm{~s})$. For the two carbons, 15 cycles (approximately $30 \mathrm{wt} \%$ ) were processed to compare the Pt NP density and size distribution, and these were analyzed to achieve an increased fuel cell performance. Commercial Pt/C (Premetek, $30 \mathrm{wt} \%$ ) was used as a comparison with the ALD catalysts.

\section{Characterization of the Pt catalysts}

The surface area and porous structure were investigated by using Brunauer-Emmett-Teller analysis (BET, Micromeritics, ASAP 2010 analyzer). The chemical bonding was identified using X-ray photoelectron spectroscopy (XPS, Thermo Electron Corporation, MICROLAB 350). Fourier transform infrared spectroscopy (FTIR, Bruker, Vertex $80 \mathrm{v}$ ) spectra were used to analyze the carbon bonding type, which were obtained from 4000 to $400 \mathrm{~cm}^{-1}\left(4 \mathrm{~cm}^{-1}\right.$ resolution) with a Vertex $80 \mathrm{v}$. Raman spectra (Nano Base, XperRamII) were obtained using a $532 \mathrm{~nm}$ laser with a power of $3.0 \mathrm{~mW}$ at room temperature. The crystallinity and crystalline size were investigated by $\mathrm{X}$-ray diffraction (XRD, Bruker, D8 ADVANCE) using $\mathrm{Cu}-\mathrm{K} \alpha 1$ radiation with a wavelength of $1.5418 \AA$. Field-emission transmission electron microscopy (FE-TEM, FEI, TALOS F200X) operating at $200 \mathrm{kV}$ was used to analyze the visible particle size, particle dispersion and density. The particle size and density of the STEM images were calculated by Image-Pro Plus processing and analysis software. To identify the electrochemical activity, cyclic voltammetry (CV, Autolab, PGSTAT302N) and oxygen reduction reaction (ORR) tests were implemented by using the three-electrode method. This method consisted of a glassy carbon electrode $5 \mathrm{~mm}$ in diameter as the working electrode, $\mathrm{Ag} / \mathrm{AgCl}$ as the reference electrode and Pt foil as the counter electrode. The potential was given versus the reversible hydrogen electrode (RHE), and $0.1 \mathrm{M} \mathrm{HClO}_{4}$ was used as the electrolyte. The glassy carbon electrode was polished with a $1 \mu \mathrm{m} \mathrm{Al} \mathrm{O}_{3}$ powder and washed with DI water before the experiments. To add the Pt catalyst onto the glassy carbon, isopropanol $(5 \mathrm{~mL})$ and Nafion ${ }^{\oplus}$ solution $(0.2 \mathrm{~mL}$ of $5 \mathrm{wt} \%$ solution) were first mixed in DI water $(39.8 \mathrm{~mL})$. Then, this solution and $5 \mathrm{mg}$ of the $\mathrm{Pt}$ catalyst were added to a vial container. To make the ink, this mixture was sonicated in the vial. Then, $15 \mu \mathrm{L}$ of the ink was deposited onto the working electrode $\left(25 \mu \mathrm{g}_{\mathrm{Pt}} /\right.$ $\mathrm{cm}^{2}$ ) and dried in a thermal oven at $80^{\circ} \mathrm{C}$. The $\mathrm{CV}$ was measured at a sweep rate of $20 \mathrm{mV} / \mathrm{s}$ in the saturated $\mathrm{Ar}$ electrolyte. Linear scan voltammetry for the ORR activity measurement was performed using a rotating disk electrode (RDE) system with a rotation speed of $1600 \mathrm{rpm}$ in an $\mathrm{O}_{2}$-saturated electrolyte at a $20 \mathrm{mV} / \mathrm{s}$ scan rate.

\section{MEA preparation}

The membrane electrode assembly (MEA) was prepared from the Pt catalyst made by ALD for both the cathode and anode as a function of Nafion ${ }^{\circledR}$ solution content. The Nafion ${ }^{\circledR}$ percentage was calculated using the following equation:

$$
\text { Nafion }{ }^{\circledR} \text { loading }=\frac{\operatorname{Nafion}\left(\frac{\mathrm{mg}}{\mathrm{cm}^{2}}\right)}{\operatorname{Nafion}\left(\frac{\mathrm{mg}}{\mathrm{cm}^{2}}\right)+\operatorname{catalyst}\left(\frac{\mathrm{mg}}{\mathrm{cm}^{2}}\right)} \times 100
$$

The catalyst ink was made by adding Nafion ${ }^{\circledR}$ solution with 2-propanol to the Pt catalyst powder. The resulting ink was sprayed directly onto one side of the pretreated dried membrane (Nafion 212) and dried by heating under vacuum at $70{ }^{\circ} \mathrm{C}$ for $30 \mathrm{~min}$. The reverse side of the membrane was also subjected to a similar process to obtain the anode and cathode catalyst layers on the membrane. The catalyst loading was adjusted to $0.1 \mathrm{mg} /$ $\mathrm{cm}^{2}$ on the anode and $0.4 \mathrm{mg} / \mathrm{cm}^{2}$ on the cathode. Both electrodes had an active surface area of $5 \mathrm{~cm}^{2}$. The MEAs were sandwiched between two gas diffusion layers (GDLs, N1S 1007, Ce Tech) and then installed in graphite plates with a serpentine flow field. All cells were operated with a relative humidity of $100 \%$ and with $\mathrm{H}_{2}$ and $\mathrm{O}_{2}$ at a cell temperature of $70^{\circ} \mathrm{C}$. To evaluate the durability of the catalysts in single cells, triangle voltage cycling tests were carried out between 0.6 and $1.0 \mathrm{~V}$ at a sweep rate of $50 \mathrm{mV} / \mathrm{s}$. The anode side was fed with hydrogen $(40 \mathrm{sccm})$ and served as the reference and counter electrodes. The cathode side was fed nitrogen $(100 \mathrm{sccm})$ and served as the working electrode. After $3 \mathrm{k}, 10 \mathrm{k}$, and $30 \mathrm{k}$ cycles, the polarization curves were measured. Electrochemical impedance spectroscopy (EIS) was measured with a $20 \mathrm{~A}$ current booster (PGSTAT30) and performed at a DC potential of $0.9 \mathrm{~V}$ with an $\mathrm{AC}$ frequency range from $10 \mathrm{k}$ $\mathrm{Hz}-0.01 \mathrm{~Hz}$ and $\mathrm{AC}$ amplitude of $5 \mathrm{mV}$ before and after the durability test.

\section{Results \\ Carbon surface characteristics}

Pt catalysts were synthesized on the fluidizing carbon supports by FBR-ALD with 15 cycles that consisted of a $\mathrm{MeCpPtMe}_{3}$ pulse, a purge, an $\mathrm{O}_{2}$ pulse and another purge, as shown in Fig. 1a. During Pt NP deposition, the textural properties (surface area, porosity, and pore volume), structural defects, and functional groups of the carbon supports can play a key role by providing abundant binding sites for anchoring the Pt NPs, enabling control of the particle density and size distribution ${ }^{19}$. Before deposition, pretreatment of the carbons was conducted in a citric acid solution to maximize the functional groups for Pt nucleation (see experimental section for details in the supporting information). The multipoint BET nitrogen adsorption-desorption isotherms for the 

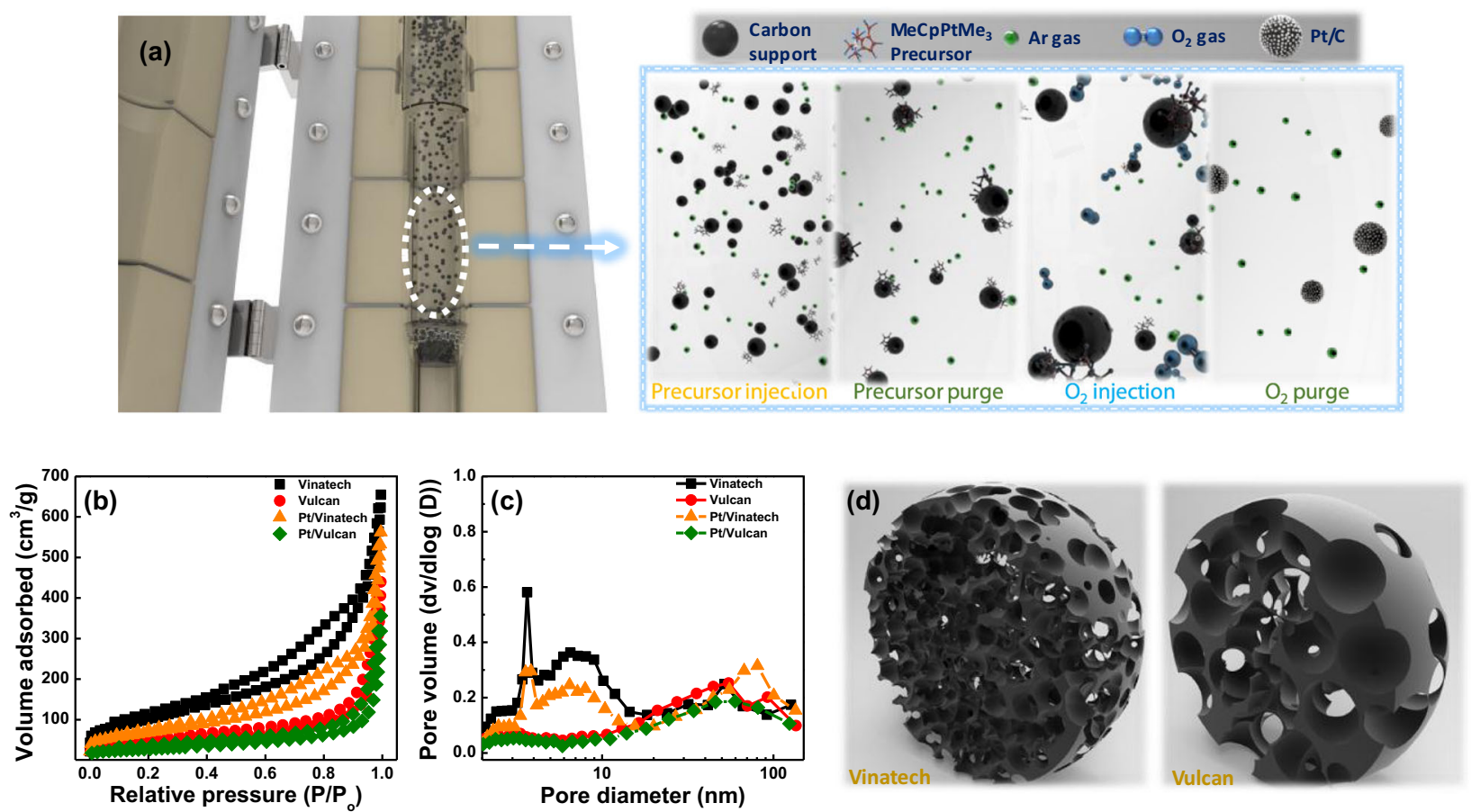

Fig. 1 Schematic FBR process and carbon textural properties. a Schematic of FBR-ALD and one cycle process. b Nitrogen adsorption and desorption isotherms of Vinatech, Vulcan, Pt/Ninatech, and Pt/Vulcan. c Pore size distribution of each sample. $\mathbf{d}$ Schematic of carbon architectures for Vinatech and Vulcan.

two different carbon supports (Vulcan and Vinatech carbons) before and after deposition were obtained to systemically reveal the effect of the textural properties on the growth mechanism of the Pt NPs produced by FBRALD. The isotherms of all the samples showed type IV characteristics with an $\mathrm{H} 3$ hysteresis loop ${ }^{42}$ (Fig. 1b), which was attributed to the presence of slit-like mesopores. The pore size distribution curves (Fig. 1c) showed that both samples exhibited mesopores and macropores ${ }^{13}$. A sharp and broader peak below $10 \mathrm{~nm}$ was attributed to the presence of a large number of mesopores in the Vinatech carbon, whereas a low intensity distribution curve for mesopores was found for the Vulcan carbon. After synthesizing the $\mathrm{Pt} /$ carbon (approximately $30 \mathrm{wt} \%$ ) support (Fig. S1), the peak intensities of the pore size distributions decreased for both carbons, suggesting $\mathrm{Pt}$ loading on the carbon support and subsequent pore filing $^{43}$. The BET specific surface area and pore volume of the bare and Pt-deposited Vulcan and Vinatech carbons are summarized in Table 1 and illustrated in Fig. 1d. The Vinatech carbon possessed a specific surface area $\left(370.92 \mathrm{~m}^{2} / \mathrm{g}\right)$ and pore volume $\left(0.9839 \mathrm{~cm}^{3} / \mathrm{g}\right)$ that was $\sim 2.5$ and 1.6 times larger than those of the Vulcan carbon $\left(145.45 \mathrm{~m}^{2} / \mathrm{g}\right.$ and $0.6135 \mathrm{~cm}^{3} / \mathrm{g}$, respectively). It was noted that the decrease in surface area of the modified Vulcan carbon (after chemical treatment) compared to that of reported Vulcan carbon ${ }^{44}$ could be due to
Table 1 Textural properties for Vinatech, Vulcan, $\mathrm{Pt} /$ Vinatech, and Pt/Vulcan.

\begin{tabular}{lll}
\hline Samples & BET surface area $\left(\mathbf{m}^{2} / \mathbf{g}\right)$ & Pore volume $\left(\mathbf{c m}^{3} \mathbf{g}\right)$ \\
\hline Vinatech & 370.92 & 0.9839 \\
Vulcan & 145.45 & 0.6135 \\
Pt on Vinatech & 242.88 & 0.8363 \\
Pt on Vulcan & 97.58 & 0.4865 \\
\hline
\end{tabular}

blockages at the entrances of the carbon pores by the resulting functional groups (Fig. S2) ${ }^{45,46}$. After Pt deposition on both carbons, the specific surface area and pore volume of both $\mathrm{Pt} /$ carbons were found to decrease compared to those of the bare carbons. However, the Pt/ Vinatech still exhibited a higher surface area and pore volume than the deposited Pt/Vulcan and even bare Vulcan carbon. It is worth mentioning that after $\mathrm{Pt}$ deposition, mesopores below $10 \mathrm{~nm}$ in the Vinatech carbon still existed in the sample, which would help the efficient transport of gas molecules and protons and enable transport of the molecules from the Pt surface.

ALD Pt deposition on a carbon support is greatly influenced by the oxygen-containing functional groups on the carbons ${ }^{25}$. To identify the state of the oxygen functional groups on the carbon supports, FTIR 



(e)

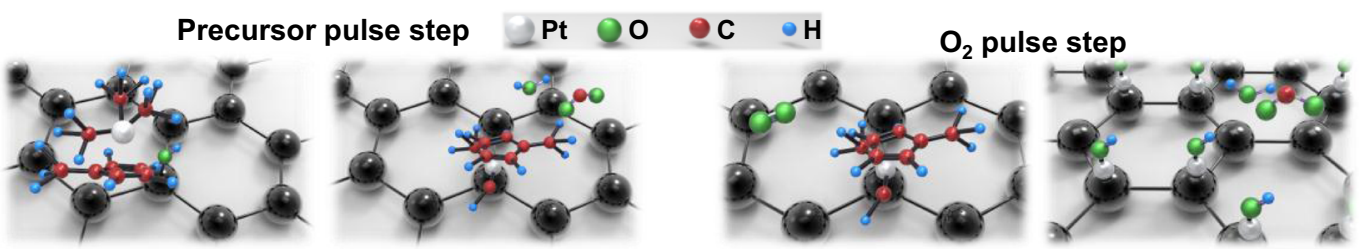

Fig. 2 Carbon surface functional group analysis. a FTIR spectra of Vinatech and Vulcan carbon black. C 1s XPS spectra of $\mathbf{b}$ Vinatech and $\mathbf{c}$ Vulcan carbon black. $\mathbf{d}$ Schematic models of surface structures in the Vinatech and Vulcan carbon. e Schematic model structures of Pt deposition steps on the carbon surface with oxygen functional groups.

Table 20 1s XPS peak fitting data of Vinatech and Vulcan carbon black.

\begin{tabular}{lcr}
\hline Bond and binding energy & Vinatech & Vulcan \\
\hline $\mathrm{C}-\mathrm{C}\left(\mathrm{sp}^{2}\right), 284.6 \mathrm{eV}$ & $39.79 \%$ & $45.64 \%$ \\
$\mathrm{C}-\mathrm{C}\left(\mathrm{sp}^{3}\right), 284.9 \mathrm{eV}$ & $32.68 \%$ & $32.76 \%$ \\
$\mathrm{C}-\mathrm{O}, 286.5 \mathrm{eV}$ & $8.37 \%$ & $6.87 \%$ \\
$\mathrm{C}=\mathrm{O}, 288.5 \mathrm{eV}$ & $19.16 \%$ & $14.72 \%$ \\
\hline
\end{tabular}

vibrational spectroscopy was carried out. The FTIR spectra of the Vinatech and Vulcan carbon supports are shown in Fig. 2a. The oxygen groups of vibrational bands at $\sim 1160 \mathrm{~cm}^{-147}, \sim 1400 \mathrm{~cm}^{-1}, 1600-1700 \mathrm{~cm}^{-148,49}$, and $3400 \mathrm{~cm}^{-1}$ correspond to the $\mathrm{C}-\mathrm{O}$ (stretching vibration), $\mathrm{O}-\mathrm{H}$ (stretching), $\mathrm{OH}$ (bending vibration) overlapped with $\mathrm{C}=\mathrm{C}$ (stretching vibration) and $\mathrm{C}=\mathrm{O}$ (stretching) groups, and $\mathrm{O}-\mathrm{H}$ (stretching vibrations) in adsorbed water, respectively. It is noted that the peak corresponding to the $\mathrm{C}-\mathrm{O}$ vibration was not found in the Vulcan carbon. It is also worth mentioning that the
Vinatech had more oxygen functional groups than Vulcan and therefore provided more binding nucleation sites for high-density Pt deposition. However, it is very difficult to distinguish the peaks of the other functional groups because of overlapping and similar peaks for both carbons. Therefore, to further clarify the oxygen functional group content of both carbons, XPS analysis was performed, as shown in Fig. 2(b, c). The $\mathrm{C} 1 s$ spectra of both carbons were deconvoluted into four components located at $284.6 \mathrm{eV}, 284.9 \mathrm{eV}, 286.5 \mathrm{eV}$, and $288.5 \mathrm{eV}$ corresponding to the $\mathrm{C}-\mathrm{C}\left(\mathrm{sp}^{2}\right), \mathrm{C}=\mathrm{C}\left(\mathrm{sp}^{3}\right)$, hydroxyl $\mathrm{C}-\mathrm{O}$, and carbonyl $\mathrm{C}=\mathrm{O}$ groups ${ }^{50}$, respectively. The relative contributions of each bond are listed in Table 2 . Compared to the Vulcan carbon (Fig. 2c), the Vinatech exhibited a lower peak intensity from $\mathrm{C}-\mathrm{C}$ bonding and a wider oxidized carbon peak (Fig. 2b). The percentage of oxygen functional groups $(\mathrm{C}-\mathrm{O}$ and $\mathrm{C}=\mathrm{O})$ in the Vinatech carbon was higher than that in Vulcan carbon (Fig. 2d). These oxidized functional groups are the key factor to growing ALD Pt particles on the carbon supports. Figure 3e shows that the Pt growth step by ALD can be formulated as follows ${ }^{29}$. 


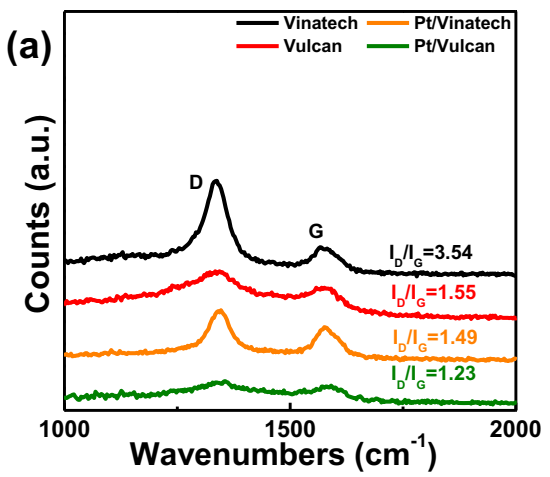

(b)

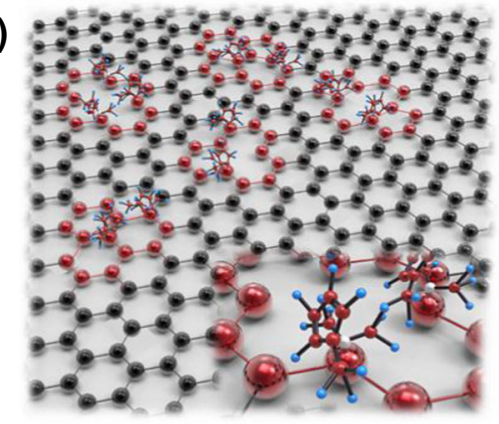

(c)

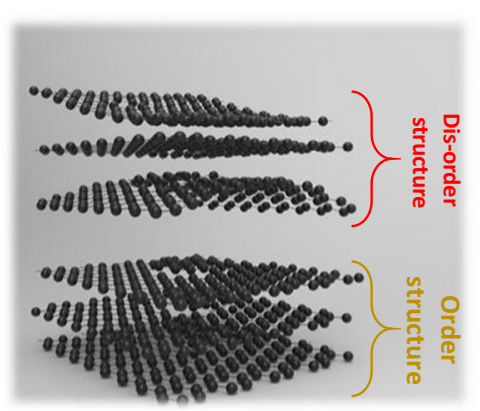

(d)

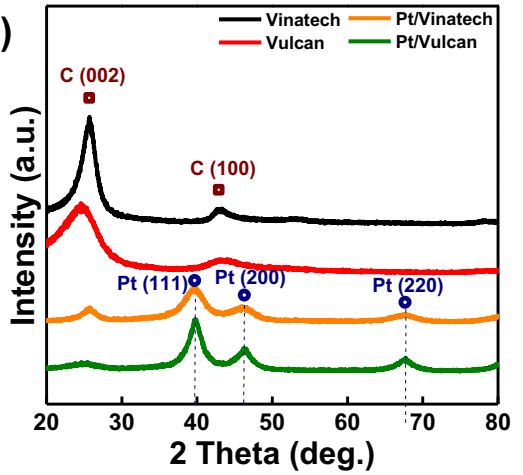

Fig. 3 Pt catalyst defect and structure analysis. a Raman spectra of the Vinatech, Vulcan, Pt/Vinatech, and Pt/Nulcan. Schematics of $\mathbf{b}$ carbon defects (red color) and $\mathbf{c}$ ordered and disordered structures. $\mathbf{d}$ XRD patterns of each sample.

\section{Precursor pulse step}

$$
\begin{gathered}
\text { Carbon support }-\mathrm{O}^{*}(\mathrm{ads})+\mathrm{MeCpPtMe}_{3}(\mathrm{~g}) \\
\begin{aligned}
\text { Carbon support }- & \mathrm{MeCpPtMe}_{2}^{*}(\mathrm{ads})+\mathrm{CO}_{2}(\mathrm{~g}) \\
& +\mathrm{H}_{2} \mathrm{O}(\mathrm{g})+\text { other products }
\end{aligned}
\end{gathered}
$$

\section{$\mathrm{O}_{2}$ pulse step}

$$
\begin{gathered}
\text { Carbon support }-\mathrm{MeCpPtMe}_{2}^{*}(\text { ads })+\mathrm{O}_{2}(\mathrm{~g}) \\
\text { Carbon support }-\mathrm{Pt}-\mathrm{O}^{*}(\text { ads })+\mathrm{CO}_{2} \\
+\mathrm{H}_{2} \mathrm{O}(\mathrm{g})+\text { other products }
\end{gathered}
$$

where ":" represents active surface species and "Carbon support $-\mathrm{O}^{*}$ " means chemisorbed oxygen on the carbon support. Based on this ALD growth mechanism, many functional groups on the surface of the carbon can be expected to provide many nucleation sites for the $\mathrm{Pt}$ deposition.

Raman spectroscopy is an important tool to reveal the structural defects and ordered/disordered structure of a carbon-based material. Raman spectra (Fig. 3a) of both carbons show the presence of two bands positioned at 1340 and $1580 \mathrm{~cm}^{-1}$, corresponding to the $\mathrm{D}$ and $\mathrm{G}$ bands, respectively. The $\mathrm{G}$ band is related to the E2g vibration mode of $\mathrm{sp}^{2}$ carbon domains and can be used to determine the degree of graphitization ${ }^{51}$. The $\mathrm{D}$ band is derived from the structural defects and disordered structures of $\mathrm{sp}^{2}$ carbon. The band intensity ratio of the Vinatech carbon support was observed to be $\mathrm{I}_{\mathrm{D}} / \mathrm{I}_{\mathrm{G}}=3.54$, which is higher than that of the Vulcan carbon support $\left(\mathrm{I}_{\mathrm{D}} / \mathrm{I}_{\mathrm{G}}=1.55\right)$. This means that the Vinatech had more structural defects (Fig. 3b) and a larger amount of disordered carbon (Fig. 3c), which can also provide more anchoring points for Pt deposition (Fig. 3b inset). However, after Pt loading on both carbons, the intensity ratio $\left(\mathrm{I}_{\mathrm{D}} / \mathrm{I}_{\mathrm{G}}\right)$ of the Pt/Vinatech and Pt/Vulcan was found to decrease to 1.55 and 1.23, respectively. It is noted that the degree of $\mathrm{I}_{\mathrm{D}} / \mathrm{I}_{\mathrm{G}}$ reduction in the Vinatech after depositing Pt NPs was $58 \%$, whereas the degree of $\mathrm{I}_{\mathrm{D}} / \mathrm{I}_{\mathrm{G}}$ reduction was $21 \%$ for the Vulcan. This indicated that after deposition, structural defects and the disordered structure of the Vinatech support were consumed as nucleation sites and arranged in an ordered structure, which can suggest a high-density Pt NP deposition on Vinatech. The XRD spectra of the bare and Pt-deposited Vulcan and Vinatech carbon supports are shown in Fig. 3d. Two peaks appearing near $25^{\circ}$ and $43^{\circ}$, which correspond to the 
(002) and (100) planes of carbon, respectively, were observed in both carbons. The (002) diffraction peak was related to the disordered carbonaceous interlayer ${ }^{52,53}$, and the (100) diffraction peak was attributed to crystalline carbon $^{54}$. High intensities of the (100) peak relative to that of the (002) peak can indicate an improved degree of graphitization. The $\mathrm{I}_{(100)} / \mathrm{I}_{(002)}$ intensity ratios of the Vinatech and Vulcan carbon supports were calculated to be 0.159 and 0.204 , respectively. This demonstrates that the Vinatech had more structural defects than the Vulcan, which is supported by the Raman spectra (Fig. 3a). Deposited Pt NPs on both carbons show the (111), (200), and (220) orientations with a Pt FCC (face-centered cubic) structure ${ }^{28}$. The grain size of $2.66 \mathrm{~nm}$ for the $\mathrm{Pt} /$ Vinatech was calculated using Scherrer's equation, and the grain size for the Pt/Vulcan was found to be $3.42 \mathrm{~nm}$. Considering the same Pt loading at approximately $30 \mathrm{wt} \%$, the Pt/Vinatech had a denser and smaller Pt NP distribution on the carbon matrix.

\section{Pt deposition formations on the carbons}

Based on the above results, it is clear that the $\mathrm{Pt}$ deposition on the carbon supports (Vinatech and Vulcan) by FBR-ALD were affected by the surface area, pore size, and oxygen functional groups on the carbon surface, as well as the presence of many structural defects and disordered carbon structures. To visibly inspect the $\mathrm{Pt}$ deposition behavior on the carbon supports, bright-field (BF) TEM images and high-angle annular dark-field (HAADF) TEM images were obtained. The images of the $\mathrm{Pt} /$ Vinatech, $\mathrm{Pt} / \mathrm{Vulcan}$, and commercial $\mathrm{Pt} /$ carbon (Premetek $30 \mathrm{wt} \%$ ) are illustrated in Fig. 4. The Pt/Vinatech sample had a very uniform Pt distribution throughout the low-magnification BF- and HADDF-TEM images (Fig. 4a). The Pt/Vulcan carbon (Fig. 4b) also appeared uniform but the uniformity was less than that of the Pt/ Vinatech, while the commercial Pt/carbon (Premetek, $30 \mathrm{wt} \%)$ had a wide Pt NP distribution range that was somewhat uniform but contained mostly nonuniform agglomerated NPs (Fig. 4c). The high-magnification TEM images measured from two parts in the low-magnification image (Fig. 4a) show a uniform and high-density Pt dispersion, indicating a wide uniformity range, which was even identified at low cycles (Fig. S3). Both the BF-TEM and HAADF images show that more uniformly distributed and denser Pt NPs formed in the Pt/Vinatech sample than in $\mathrm{Pt} / \mathrm{Vulcan}$ and commercial $\mathrm{Pt} /$ carbon samples. In addition, the HAADF image of the Pt/Vinatech exhibited a denser amount of more visible Pt NPs compared to those in the BF-TEM image. This means that Vinatech possessed a highly porous structure inside, in which many Pt NPs were deposited. In addition, this result demonstrated that the favorable textural properties and abundant structural defects, disorder and functional groups on the Vinatech carbon during the ALD process provided a larger number of active sites that anchored many Pt NPs inside the carbon surface compared to those of the other carbons ${ }^{16}$.

To summarize the Pt distribution and density, numerical figures for the particle size, distribution and density are shown in Fig. 5. To provide relatable values, they were calculated and averaged from the respective HAADF images in Fig. 4 and S4. Narrow and small Pt particle size (1.5-2.5 nm) distributions on the Vinatech (Fig. 5a) were observed, while Pt/Vulcan exhibited a $2-3 \mathrm{~nm}$ particle size with a small width distribution (Fig. 5b). The commercial Pt/carbon was found to have a larger Pt particle size of $1.5-3 \mathrm{~nm}$ with a wider particle dispersion than those for the $\mathrm{Pt} /$ Vinatech or $\mathrm{Pt} / \mathrm{Vulcan}$. Based on this, ALD provided a uniform Pt particle deposition on the carbon supports (Vinatech and Vulcan) compared to that on the commercial Pt/carbon catalyst (Fig. 5c) synthesized by the wet process. However, the Vinatech was a better supporting material for uniform Pt deposition than the Vulcan. As seen in the TEM image (Fig. 4a), the Pt/ Vinatech exhibited a Pt particle density that was approximately 1.6 times denser than that on the $\mathrm{Pt} / \mathrm{Vul}$ can (Fig. 5d). Although the Pt loading was similar, the Vinatech provided more uniform and smaller Pt NPs; ultimately, the Vinatech produced a denser Pt NP distribution than the Pt/Vulcan. Compared to those for the $\mathrm{Pt} / \mathrm{Vulcan}$, the commercial $\mathrm{Pt} /$ carbon exhibited a lower density with a wide range of particle densities.

\section{Electrochemical performance of the Pt catalysts}

To demonstrate the Pt catalyst activity by FBR-ALD, the $\mathrm{CV}$ curves of $\mathrm{Pt} /$ Vinatech, $\mathrm{Pt} / \mathrm{Vulcan}$ and commercial $\mathrm{Pt} /$ carbon catalyst in $0.1 \mathrm{M} \mathrm{HClO}_{4}$ with a $20 \mathrm{mV} / \mathrm{s}$ sweep are illustrated in Fig. 6a. The peaks consist of three parts: the hydrogen adsorption-desorption region (from 0.05 to $0.3 \mathrm{~V}$ ), the double layer region (from 0.3 to $0.7 \mathrm{~V}$ ) and the surface Pt oxidation region (from 0.7 to $1.2 \mathrm{~V}$ ) ${ }^{55}$. From the hydrogen desorption region, the ECSA can be determined and calculated from the following equation ${ }^{56}$ :

$$
\mathrm{ECSA}=\frac{\mathrm{Q}_{\mathrm{H}}}{[\mathrm{Pt}] \times 0.21}
$$

where " $\mathrm{Q}_{\mathrm{H}}$ " represents the charge for hydrogen desorption $\left(\mathrm{mC} / \mathrm{cm}^{2}\right)$, "[Pt]" is the Pt loading on the glassy carbon electrode $\left(\mathrm{mg} / \mathrm{cm}^{2}\right)$, and the number " 0.21 " represents the charge required to oxidize the adsorption of the $\mathrm{H}_{2}$ monolayer on the Pt surface. The ECSAs of the $\mathrm{Pt} /$ Vinatech, Pt/Vulcan and commercial Pt/carbon catalysts were found to be $90.8,78.9$, and $72.6 \mathrm{~m}^{2} / \mathrm{g}$, respectively. Considering the same amount of Pt loading in the respective samples, the Pt NPs in the Pt/Vulcan and commercial $\mathrm{Pt} /$ carbon possessed a low active surface area 


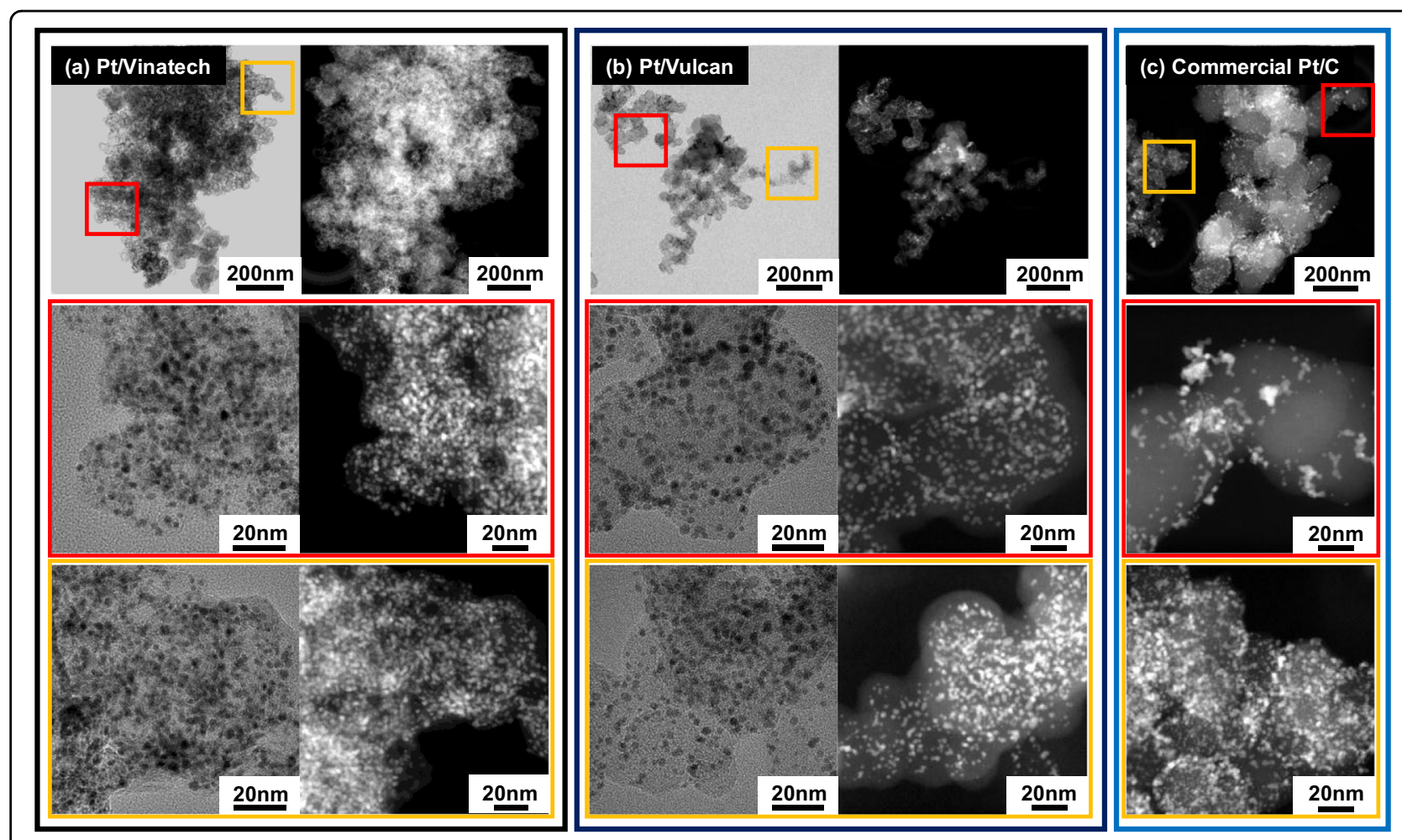

Fig. 4 Pt catalyst TEM image. BF-TEM images and HAADF-TEM mode images at the same positions of a Pt/Ninatech, $\mathbf{b}$ Pt/Nulcan, and c commercial Pt/C.

owing to the larger particle size with a low density, while the high Pt dispersion with a fine particle size in the Vinatech (illustrated in Fig. 6b) provided a large number of accessible active surface areas for catalytic reaction. However, a higher ECSA was obtained for the Pt/Vulcan than that for the commercial Pt catalyst with its partially agglomerated and nonuniform Pt distribution, as seen from the TEM image (Fig. 4c). Figure 6c displays the ORR polarization curves measured in an $\mathrm{O}_{2}$-saturated $0.1 \mathrm{M}$ $\mathrm{HClO}_{4}$ solution using the RDE at $1600 \mathrm{rpm}$. The Pt/ Vintech showed a higher ORR activity than the Pt/Vulcan. This can be due to the efficient charge transfer of uniformly dispersed and dense Pt NPs in the Pt/Vinatech. However, the ORR activity of the Pt/Vulcan was even higher than that of the commercial Pt catalyst.

\section{Performance and durability of the PEMFC cells}

The relative particle density and distribution can influence the optimization of ionomer content, as well as the performance of the MEA tests. Polarization curves from the PEMFC with ALD Pt/both-carbons and commercial $\mathrm{Pt} /$ carbon catalyst are shown in Fig. 7 as a function of Nafion ${ }^{\circledast}$ content. In addition, power density curves were also obtained (Fig. S5). The electrode performance of the $\mathrm{Pt} /$ Vinatech was found to increase with increasing Nafion ${ }^{\circledast}$ content from 25 to $35 \mathrm{wt} \%$, which had the maximum electrode performance, and then it eventually decreased until a Nafion ${ }^{\circledR}$ content of $45 \mathrm{wt} \%$ was reached (Fig. 7a). Many studies have been reported to reveal PEMFC characteristics with different ionomer contents ${ }^{57-}$ ${ }^{59}$. As illustrated in Fig. 7d, at a low ionomer content, a poor electrode performance was observed from the high cell impedance, which was due to the discontinuous proton-conducting ionomer networks, few three-phase interfaces and poor contact between the electrolyte with the catalyst ${ }^{60}$. On the other hand, a high ionomer content caused the blocking of the catalyst sites from the gas molecules, resulting in a lowered gas permeability and an increase in the mass transport distance ${ }^{59}$. The Pt/Vulcan showed the efficient cell performance of $\mathrm{Nafion}^{\circledR}$ at $25 \mathrm{wt}$ $\%$, indicating that a lower Nafion ${ }^{\circledR}$ content was needed for the optimization than that needed for the Vinatech (Fig. $7 \mathrm{~b})$. A similar and optimized $25 \mathrm{wt} \% \mathrm{Nafion}^{\circledR}$ content for the commercial Pt/carbon catalyst was obtained by controlling the Nafion ${ }^{\circledR}$ from 20 to $30 \mathrm{wt} \%$ (Fig. 7c). These results can be explained by the Pt catalyst surface areas, as shown in Fig. 1 and Table 1. According to previous reports $^{61}$, the ionomer content is highly dependent on the catalyst surface area. All Pt catalyst surfaces should be wrapped by the Nafion ${ }^{\circledast}$ ionomer for efficient three-phase interfaces, and then the ionomer can maintain its network with the catalyst ${ }^{9}$. Therefore, the content of ionomers 



Fig. 5 Pt NPs size histrogram and density. Particle size of a Pt/Ninatech, b Pt/Nulcan, and c commercial Pt/C. $\mathbf{d}$ Areal density of all samples.

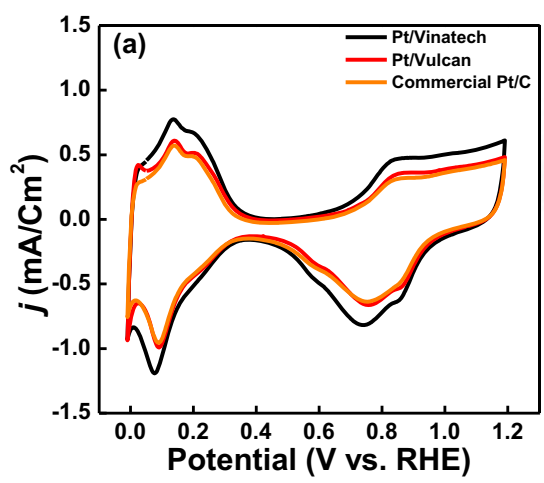

(b)

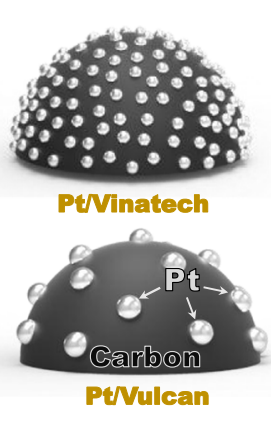

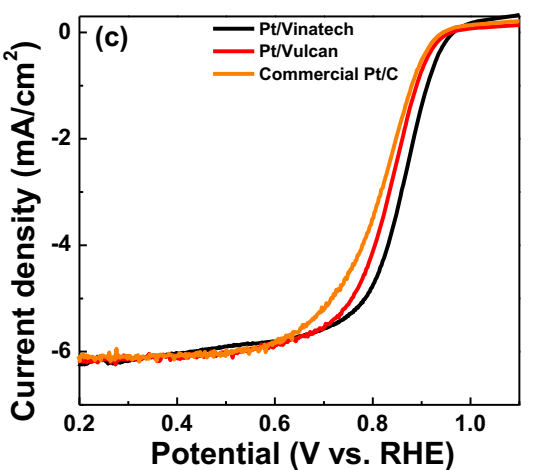

Fig. 6 Electrochemical analysis. a Cyclic voltammograms for Pt/Vinatech, Pt/Nulcan, and commercial Pt/C. b Schematic representation of Pt NP size and dispersion in Pt/Vinatech and Pt/Nulcan. c The ORR polarization curves of the respective catalysts in an $\mathrm{O}_{2}$-saturated $0.1 \mathrm{M} \mathrm{HClO}_{4}$ solution.

would be high for a Pt catalyst with a large surface area, resulting in a considerable Nafion ${ }^{\circledR}$ content being needed for the Pt/Vinatech with the highest BET surface area herein, while both the Pt/Vulcan and commercial Pt/ carbon catalyst were optimized with a lower amount of 25 wt\% Nafion ${ }^{\circledast}$, probably due to the comparable surface area. At the optimized Nafion ${ }^{\circledast}$ content, the current density at $0.6 \mathrm{~V}$ was found to be $1.55,1.46$, and $1.42 \mathrm{~A} /$ $\mathrm{cm}^{2}$ for the Pt/Vinatech, Pt/Vulcan and commercial Pt/ carbon, respectively (Table 3 ). This result can be explained by the Pt active surface area. The Pt/Vinatech shows the best performance with the highest mass activity (Fig. S6) in the MEA test due to its high ECSA ${ }^{62}$.

The durability of Pt catalysts under the operating conditions of fuel cells can be influenced by the size, uniform dispersion and density of Pt NPs. To investigate the stability of the Pt/Vinatech and Pt/Vulcan, a cycling degradation test for a single cell was conducted between 0.6 and 



Insufficient ionomer Excess ionomer

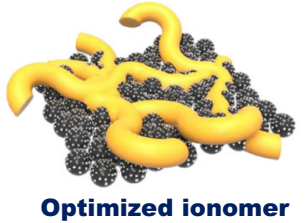

Fig. 7 MEA properties and optimization. Polarization curves for a Pt/Ninatech, $\mathbf{b}$ Pt/Nulcan, and $\mathbf{c}$ commercial Pt/C as a function of Nafion ${ }^{\bullet}$ wt\%. The Pt loading on the anode and cathode were $0.1 \mathrm{mgpt} / \mathrm{cm}^{2}$ and $0.4 \mathrm{mgpt} / \mathrm{cm}^{2}$, respectively. The measurements were carried out with $\mathrm{H}_{2} / \mathrm{O}_{2}$ at a cell temperature of $70^{\circ} \mathrm{C}$ and ambient pressure. $\mathbf{d}$ Schematic illustration of the catalyst layers according to the ionomer contents.

Table 3 The current density of MEAs at $0.6 \mathrm{~V}$ with different Nafion ${ }^{\circledR}$ concentrations for $\mathrm{Pt} / \mathrm{Vinatech}, \mathrm{Pt} / \mathrm{Vulcan}$, and commercial Pt/C.

\begin{tabular}{|c|c|c|c|c|c|}
\hline $\begin{array}{l}\text { Vinatech } 30 \mathrm{wt} \\
\% \mathrm{Pt} / \mathrm{C}\end{array}$ & $\begin{array}{l}\text { Current density } \\
\left(\mathrm{A} / \mathrm{cm}^{2}\right) \text { at } 0.6 \mathrm{~V}\end{array}$ & $\begin{array}{l}\text { Vulcan } 30 \text { wt } \\
\% \mathrm{Pt} / \mathrm{C}\end{array}$ & $\begin{array}{l}\text { Current density } \\
\left(\mathrm{A} / \mathrm{cm}^{2}\right) \text { at } 0.6 \mathrm{~V}\end{array}$ & $\begin{array}{l}\text { Commercial (Premetek) } \\
\mathrm{Pt} / \mathrm{C} 30 \mathrm{wt} \%\end{array}$ & $\begin{array}{l}\text { Current density } \\
\left(\mathrm{A} / \mathrm{cm}^{2}\right) \text { at } 0.6 \mathrm{~V}\end{array}$ \\
\hline Nafion 25 wt $\%$ & 1.45 & Nafion 15 wt\% & 1.33 & & \\
\hline Nafion 30 wt $\%$ & 1.53 & Nafion 20 wt $\%$ & 1.42 & Nafion 20 wt\% & 1.41 \\
\hline Nafion 35 wt $\%$ & 1.55 & Nafion 25 wt $\%$ & 1.46 & Nafion 25 wt\% & 1.42 \\
\hline Nafion 40 wt $\%$ & 1.51 & Nafion 30 wt $\%$ & 1.44 & Nafion 30 wt\% & 1.33 \\
\hline Nafion 45 wt\% & 1.41 & Nafion 35 wt $\%$ & 1.38 & & \\
\hline
\end{tabular}

$1 \mathrm{~V}$ at a scan rate of $50 \mathrm{mV} / \mathrm{s}$ (Fig. 8). After a $3 \mathrm{k}$ potential cycle, the performance of the fuel cell with $\mathrm{Pt} /$ Vinatech increased to $1.7 \%$ in terms of the current density $(1.58 \mathrm{~A} /$ $\mathrm{cm}^{2}$ ) (Fig. 8a) at $0.6 \mathrm{~V}$, as well as the power density (Fig. S7), whereas that with Pt/Vulcan (Fig. 8b) and commercial $\mathrm{Pt} /$ carbon decreased to $1.38 \mathrm{~A} / \mathrm{cm}^{2}$ and $1.33 \mathrm{~A} / \mathrm{cm}^{2}$, respectively (Fig. 8c, d). The initial increase in the performance of the $\mathrm{Pt} /$ Vinatech could indicate that initially, all Pt NPs, especially inside the porous cavity of the carbon, were not exposed to the catalytic reaction and did not participate in it due to the large pore depth of the Vinatech carbon, but it is expected that these NPs were activated after the gradual cycling test. This can also be explained by the ECSA behavior before and after the MEA cycling test (Fig. S8). After 10k potential cycles, the current density of the $\mathrm{Pt} /$ Vinatech started to be decreased similar to Pt/Vulcan and commercial Pt/C. After $30 \mathrm{k}$ potential cycles, the $\mathrm{Pt} /$ Vinatech showed a reduction $(81.5 \%)$ in the performance, which is similar to that for the $\mathrm{Pt} /$ Vulcan $(80.1 \%)$, but still showed the highest current density $\left(1.26 \mathrm{~A} / \mathrm{cm}^{2}\right)$ (Fig. 8e). The decreased interparticle distance $^{63,64}$ of dense and small Pt NPs ${ }^{65}$ may promote the formation of large NPs via aggregation due to the Ostwald ripening mechanism, resulting in a deteriorated 


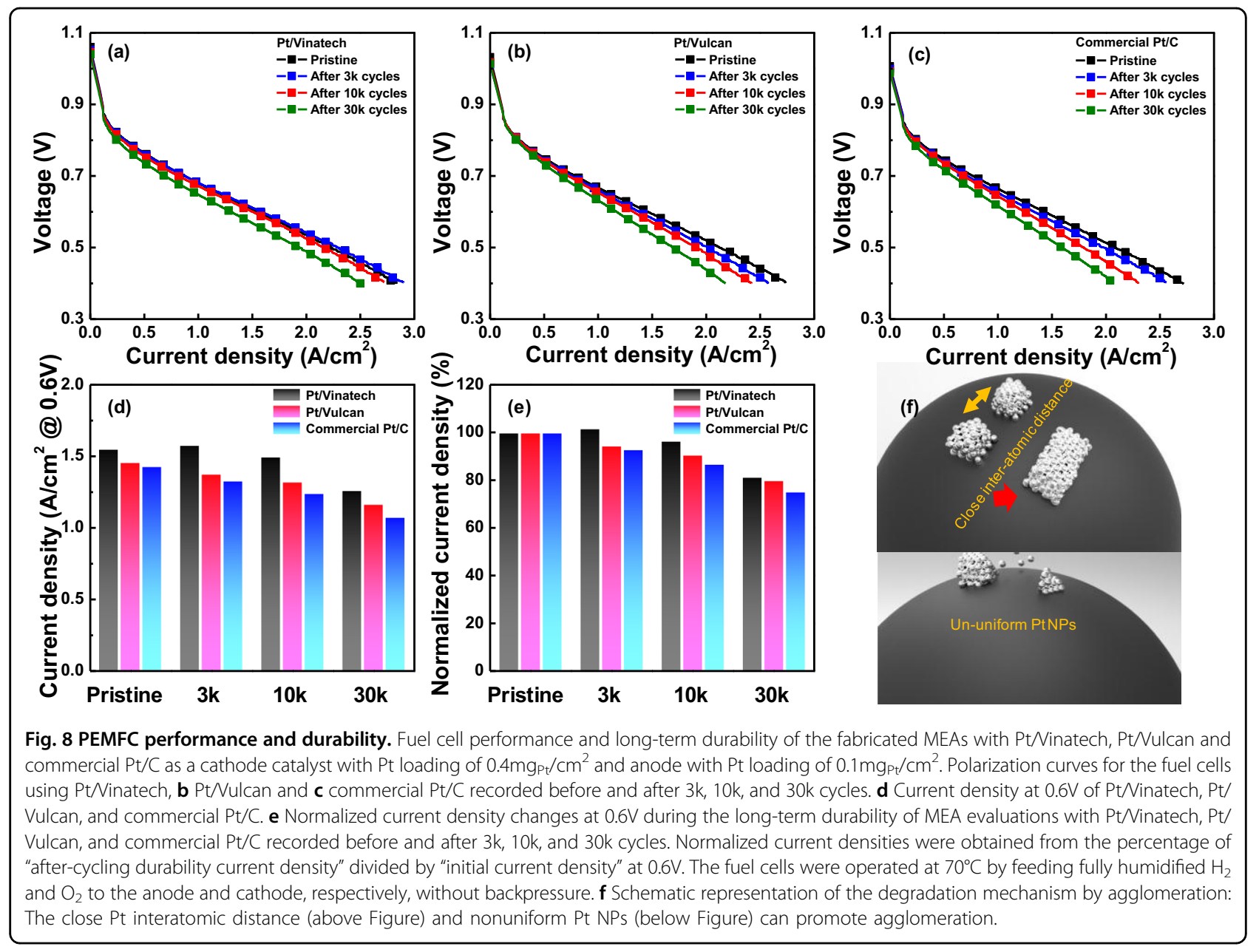

cell performance for the Pt/Vinatech owing to a decline in the Pt surface area (Fig. 8f above schematic) ${ }^{63}$. Nevertheless, the Pt/Vinatech showed excellent fuel cell durability due to the uniform distribution and size of the Pt NPs in the carbon matrix (Fig. $8 f$ below schematic). Furthermore, compared to those for the commercial Pt/C, both catalysts using Pt prepared with FBR-ALD showed better performance and stability due to the homogeneously deposited Pt NPs on both carbons, which was also maintained after the stability testing, according to the TEM analysis (Fig. S9). The cell performance resulting from their well-dispersed characteristics can also be supported by their efficient charge transfer measured by EIS and HRF (Fig. S10). Thus, the FBR-ALD technique is an efficient approach to synthesize uniform Pt catalysts depending on the functionalized surface of the carbon substrate to improve MEA performance and long-term durability.

\section{Conclusions}

In summary, the synthesis of Pt NPs with $30 \mathrm{wt} \% \mathrm{Pt}$ loading was conducted on two different carbon supports, Vinatech and Vulcan, by using the FBR-ALD method. The nucleation of the Pt NPs was influenced by the textural properties (e.g., surface area, porosity, and pore volume), structural surface defects and carbon functional groups. The structural characterization showed that an improved uniformity and denser Pt dispersion formed on the Vinatech compared to those for the Vulcan at the same weight percent due to its higher surface area with a large pore volume, abundant structural defects and more oxygen functional groups. The uniform architecture of the $\mathrm{Pt} /$ Vinatech resulted in a higher ECSA than those of the $\mathrm{Pt} /$ Vulcan and commercial catalyst. Finally, the MEA fuel cell performance showed that Pt/Vinatech needed a high Nafion ${ }^{\circledast}$ content due to its densely dispersed Pt NPs. At an optimized Nafion ${ }^{\circledR}$ content, the highest MEA performance was found for the Pt/Vinatech compared to those for the Pt/Vulcan and commercial samples due to its higher ECSA resulting from the uniform and dense ALDPt dispersion on the Vinatech carbon support. In fact, the Pt catalysts using FBR-ALD possessed significant longterm stability for the MEA test compared to commercial samples. This study can be a guideline for synthesizing Pt NPs on carbons using the dry ALD process in the catalyst 
field of PEMFC stacks. In addition, selection of an effective carbon and deposition characteristics for the NPs that are optimized for the carbon properties can enhance the electrochemical and fuel cell performance and provide a way to improve the efficiency and, ultimately, commercialize PEMFCs.

\section{Acknowledgements}

This work was supported by the Global Frontier R\&D Program (2013-073298) on Center for Hybrid Interface Materials (HIM) funded by the Ministry of Science, ICT and Future Planning, and partially supported by the National Research Foundation of Korea (NRF) grant funded by the Korea government (MSIT) (No. 2020R1A2C1014841). The authors would like to thank Dr. JongSeong Bae, Miss Jong-Ah Chae, and Miss Seong-Hee Jeong for help with XPS, TEM, and BET investigations.

\section{Author details}

'School of Materials Science and Engineering, Pusan National University, 30 Jangjeon-Dong Geumjeong-Gu, Busan 46241, Republic of Korea. ${ }^{2}$ Materials Development Center, Hyundai Motor Company, 37 Cheoldobangmulgwan-ro, Uiwang-si, Gyeonggi-do 16082, Republic of Korea. ${ }^{3}$ Department of Materials Science and Engineering, Korea Advanced Institute of Science and Technology, 291 Daehak-ro Yuseong-gu, Daejeon 34141, Republic of Korea

\section{Conflict of interest}

The authors declare that they have no conflict of interest.

\section{Publisher's note}

Springer Nature remains neutral with regard to jurisdictional claims in published maps and institutional affiliations.

Supplementary information is available for this paper at https://doi.org/ 10.1038/s41427-020-0223-x.

Received: 20 October 2019 Revised: 18 March 2020 Accepted: 25 March 2020.

Published online: 12 June 2020

\section{References}

1. Wee, J. H. Applications of proton exchange membrane fuel cell system. Renew. Sust. Energ. Rev. 11, 1720-1738 (2007).

2. Ghenciu, A. F. Review of fuel processing catalysts for hydrogen production in PEM fuel cell systems. Curr. Opin. Solid. St. M. 6, 389-399 (2002).

3. Mehta, V. \& Cooper, J. S. Review and analysis of PEM fuel cell design and manufacturing. J. Power Sources 114, 32-53 (2003).

4. Wang, J. X. et al. Oxygen reduction on well-defined core-shell nanocatalysts: particle size, facet, and Pt shell thickness effects. J. Am. Chem. Soc. 131, 17298-17302 (2009)

5. Gasteiger, H. A., Kocha, S. S., Sompalli, B. F. \& Wagner, T. Activity benchmarks and requirements for Pt, Pt-alloy, and non-Pt oxygen reduction catalysts for PEMFCs. Appl. Catal. B-Environ. 56, 9-35 (2005).

6. Kang, G. S., Jin, S. C. \& Hur, S. H. Durability improvement of Pt/RGO catalysts for PEMFC by low-temperature self-catalyzed reduction. Nanoscale Res. Lett. 10, 257 (7p) (2015)

7. Zhou, Z-M. et al. Durability study of Pt-Pd/C as PEMFC cathode catalyst. Int. J. Hydrog. Energy 35, 1719-1726 (2010).

8. Castanheira, L. et al. Carbon corrosion in proton-exchange membrane fuel cells: from model experiments to real-life operation in membrane electrode assemblies. ACS Catal. 4, 2258-2267 (2014).

9. Subbaraman, R., Strmenik, D., Paulikas, A. P., Stamenkovic, V. R. \& Markovic, N. M. Oxygen reduction reaction at three-phase interfaces. ChemPhysChem 11, 2825-2833 (2010)

10. Malagoli, M., Liu, M. L., Park, H. C. \& Bongiorno, A. Protons crossing triple phase boundaries based on a metal catalyst, $\mathrm{Pd}$ or $\mathrm{Ni}$, and barium zirconate. Phys. Chem. Chem. Phys. 15, 12525-12529 (2013).
11. Wang, M. et al. Hierarchically 3D porous films electrochemically constructed on gas-liquid-solid three-phase interface for energy application. J. Mater. Chem. A 5, 9488-9513 (2017).

12. Long, Z. et al. Micro galvanic cell to generate PtO and extend the triple-phase boundary during self-assembly of Pt/C and nafion for catalyst layers of PEMFC. ACS Appl. Mater. Interfaces 9, 38165-38169 (2017).

13. Yarlagadda, V. et al. Boosting fuel cell performance with accessible carbon mesopores. ACS Energy Lett. 3, 618-621 (2018).

14. $\mathrm{Du}, \mathrm{H}$. et al. Influences of mesopore size on oxygen reduction reaction catalysis of Pt carbon aerogels. J. Phys. Chem. C. 11, 2040-2043 (2007).

15. Xu, J. B. \& Zhao, T. S. Mesoporous carbon with uniquely combined electrochemical and mass transport characteristics for polymer electrolyte membrane fuel cells. RSC Adv. 3, 16-24 (2013).

16. Park, Y. C., Tokiwa, H., Kakinuma, K., Watanabe, M. \& Uchida, M. Effects of carbon supports on Pt distribution, ionomer coverage and cathode performance for polymer electrolyte fuel cells. J. Power Sources 315, 179-191 (2016).

17. Jak, M. J. J., Konstapel, C., Kreuningen, A., van, Verhoeven, J. \& Frenken, J. W. M. Scanning tunnelling microscopy study of the growth of small palladium particles on TiO2(110). Surf. Sci. 457, 295-310 (2000).

18. Ito, T. et al. Three-dimensional spatial distributions of Pt catalyst nanoparticles on carbon substrates in polymer electrolyte fuel cells. Electrochemistry $\mathbf{7 9}$ 374-376 (2011)

19. Bell, G. R., Dawson, P. M., Pandey, P. A., Wilson, N. R. \& Mulheran, P. A. Size dependent mobility of gold Nano-clusters during growth on chemically modified graphene. APL Mater. 2, 012109-1 8 (2014) .

20. Xin, L. et al. Understanding Pt nanoparticle anchoring on graphene supports through surface functionalization. ACS Catal. 6, 2642-2653 (2016).

21. Lubers, A. M., Muhich, C. L., Anderson, K. M. \& Weimer, A. W. Mechanistic studies for depositing highly dispersed Pt nanoparticles on carbon by use of trimethyl-(methylcyclopentadienyl) platinum(IV) reactions with $\mathrm{O} 2$ and H2. J. Nanopart. Res. 17, 179 (16p) (2015).

22. Nores-Pondal, F. J. et al. Catalytic activity vs. size correlation in platinum catalysts of PEM fuel cells prepared on carbon black by different methods. Int. J. Hydrog. Energy 34, 8193-8203 (2009).

23. Litster, S. \& McLean, G. PEM fuel cell electrodes. J. Power Sources 130, 61-76 (2004).

24. Sasaki, K. et al. Ultra-low platinum content fuel cell anode electrocatalyst with a long-term performance stability. Electrochim. Acta 49, 3873-3877 (2004).

25. Haug, A. T. et al. Increasing proton exchange membrane fuel cell catalyst effectiveness through sputter deposition. J. Electrochem. Soc. 149, A280-A287 (2002).

26. Cha, S. Y. \& Lee, W. M. Performance of proton exchange membrane fuel cell electrodes prepared by direct deposition of ultrathin platinum on the membrane surface. J. Electrochem. Soc. 146, 4055-4060 (1999).

27. Wee, J. H., Lee, K. Y. \& Kim, S. H. Fabrication methods for low-Pt-loading electrocatalysts in proton exchange membrane fuel cell systems. J. Power Sources 165, 667-677 (2007).

28. Singh, S. \& Datta, J. Size control of Pt nanoparticles with stabilizing agent for better utilization of the catalyst in fuel cell reaction. J. Master Sci. 45, 3030-3040 (2010).

29. Juang, R. S. et al. Size-controlled platinum nanoparticles prepared by modifiedversion atomic layer deposition for ethanol oxidation. J. Power Sources $\mathbf{2 7 5}$ 845-851 (2015).

30. King, J. S. et al. Ultralow loading Pt nanocatalysts prepared by atomic layer deposition on carbon aerogels. Nano Lett. 8, 2405-2409 (2008).

31. Liu, C., Wang, C. C., Kei, C.-C., Hsueh, Y.-C. \& Perng, T.-P. Atomic layer deposition of platinum nanoparticles on carbon nanotubes for application in protonexchange membrane fuel cells. Small 5, 1535-1538 (2009).

32. $\mathrm{Xu}, \mathrm{S}$. et al. Extending the limits of $\mathrm{Pt} / \mathrm{C}$ catalysts with passivation-gasincorporated atomic layer deposition. Nat. Catal. 1, 624-630 (2018).

33. Ting, S. et al. Fabrication of platinum electrocatalysts on carbon nanotubes using atomic layer deposition for proton exchange membrane fuel cells. Electrochim. Acta 75, 101-107 (2012).

34. Adhikari, S., Selvaraj, S. \& Kim, D.-H. Progress in powder coating technology using atomic layer deposition. Adv. Mater. Interfaces 5, 1800581(20p) (2018).

35. McCormick, J. A., Cloutier, B. L., Weimer, A. W. \& George, S. M. Rotary reactor for atomic layer deposition on large quantities of nanoparticles. J. Vac. Sci. Technol. A 25, 67-74 (2007).

36. Lakoma, E. L., Haukka, S. \& Suntola, T. Analytical and chemical techniques in the study of surface species in atomic layer epitaxy. Thin Solid Films $\mathbf{2 2 5}$ 280-283 (1993) 
37. O'Neill, B. J. et al. Catalyst design with atomic layer deposition. ACS Catal. 5, 1804-1825 (2015).

38. Lubers, A. M., Drake, A. W., Ludlow, D. J. \& Weimer, A. W. Electrochemical hydrogen pumping using a platinum catalyst made in a fluidized bed via atomic layer deposition. Powder Technol. 296, 72-78 (2016).

39. Hsieh, C.-T., Chen, W.-Y., Tzou, D.-Y., Roy, A. K. \& Hsiao, H.-T. Atomic layer deposition of Pt nanocatalysts on graphene oxide nanosheets for electro-oxidation of formic acid. Int. J. Hydrog. Energy 37, 17837-17843 (2012).

40. Pyeon, J. J. et al. Control of the initial growth in atomic layer deposition of $\mathrm{Pt}$ films by surface pretreatment. Nanotechnology 26, 304003(9p) (2015).

41. Liang, G. et al. Influence of surface preparation on atomic layer deposition of Pt films. J. Semicond. 33, 083003-1 5 (2012).

42. Yu, Z., Piao, J. \& Liang, Z. Synthesis of $2 \mathrm{D}$ nitrogen-doped mesoporous carbon catalyst for oxygen reduction reaction. Materials 10, 197(10p) (2017).

43. Shen, $W$. et al. The effect of carbon precursor on the pore size distribution of mesoporous carbon during templating synthesis process. Mater. Lett. $\mathbf{6 0}$, 3517-3521 (2006).

44. Carmo, M., Santos, A. R. D., Poco, J. G. R. \& Linardi, M. Physical and electrochemical evaluation of commercial carbon black as electrocatalysts supports for DMFC applications. J. Power Sources 173, 860-866 (2007).

45. Carmo, M., Linardi, M. \& Poco, J. G. R. H2O2 treated carbon black as electrocatalyst support for polymer electrolyte membrane fuel cell applications. Int. J. Hydrog. Energy 33, 6289-6297 (2008).

46. Carmo, M., Linardi, M. \& Poco, J. G. R. Characterization of nitric acid functionalized carbon black and its evaluation as electrocatalyst support for direct methanol fuel cell applications. Appl. Catal. A-Gen. 355, 132-138 (2009).

47. Hadoun, H., Sadaoui, Z., Souami, N., Sahel, D. \& Toumert, I. Characterization of mesoporous carbon prepared from date stems by $\mathrm{H} 3 \mathrm{PO} 4$ chemical activation. Appl. Surf. Sci. 280, 1-7 (2013).

48. Wei, X.-X. et al. Advanced visible-light-driven photocatalyst BiOBr-TiO2graphene composite with graphene as a nano-filler. J. Mater. Chem. A. 2 4667-4675 (2014).

49. Duranoğlu, D., Trochimczuk, A. W. \& Beker, Ü. A comparison study of peach stone and acrylonitrile-divinylbenzene copolymer based activated carbons as chromium(VI) sorbents. Chem. Eng. J. 165, 56-63 (2010).

50. Liu, F., Sun, F. \& Pan, Q. Highly compressible and stretchable superhydrophobic coating inspired by bio-adhesion of marine mussels. J. Mater. Chem. A 2, 11365-11371 (2014).

51. Son, D. I. et al. Emissive ZnO-graphene quantum dots for white-light-emitting diodes. Nat. Nanotechnol. 7, 465-471 (2012).
52. Park, S.-J. \& Jang, Y.-S. Preparation and characterization of activated carbon fibers supported with silver metal for antibacterial behavior. J. Colloid Interface Sci. 261, 238-243 (2003).

53. Bikshapathi, M., Mandal, S., Mathur, G. N., Sharma, A. \& Verma, N. Modification of activated carbon fiber by metal dispersion and surface functionalization for the removal of 2-chloroethanol. Ind. Eng. Chem. Res. 50, 13092-13104 (2011).

54. Wang, H., Da, H., Ji, S., Liao, S. \& Wang, R. Selenium-functionalized carbon as a support for platinum nanoparticles with improved electrochemical properties for the oxygen reduction reaction and CO tolerance. J. Electrochem. Soc. 160, H266-H270 (2013).

55. Sheng, W., Chen, S., Vescovo, E. \& Shao-Horn, Y. Size influence on the oxygen reduction reaction activity and instability of supported Pt nanoparticles. J. Electrochem. Soc. 159, B96-B103 (2012)

56. Pozio, A., Francesco, M. D., Cemmi, A., Cardellini, F. \& Giorgi, L. Comparison of high surface Pt/C catalysts by cyclic voltammetry. J. Power Sources 105, 13-19 (2002).

57. Gamburzev, S. \& Appleby, A. J. Recent progress in performance improvement of the proton exchange membrane fuel cell (PEMFC). J. Power Sources 107, 5-12 (2002).

58. Qi, Z. \& Kaufman, A. Low Pt loading high performance Cathodes for PEM fuel cells. J. Power Sources 113, 37-43 (2003).

59. Antolini, E., Giorgi, L., Pozio, A. \& Passalacqua, E. Influence of nafion loading in the catalyst layer of gas-diffusion electrodes for PEMFC. J. Power Sources 77, 136-142 (1999).

60. Passalacqua, E., Lufrano, F., Squadrito, G. \& Giorhi, L. Nafion content in the catalyst layer of polymer electrolyte fuel cells: effects on structure and performance. Electrochim. Acta 46, 799-805 (2001).

61. Choi, S.-H. et al. Optimum content of nafion ionomer for the fabrication of MEAs in PEMFCs with spray-coated Pt/CNT electrodes. Met. Mater. Int. 17, 811-816 (2011).

62. Kim, K-H. et al. The effects of nafion ionomer content in PEMFC MEAs prepared by a catalyst-coated membrane (CCM) spraying method. Int. J. Hydrog. Energy 35, 2119-2126 (2010)

63. Meier, J. C. et al. Design criteria for stable Pt/C fuel cell catalysts, beilstein. J. Nanotechnol. 5, 44-67 (2014).

64. Yang, D. et al. Sphere-to-multipod transmorphic change of nanoconfined Pt electrocatalyst during oxygen reduction reaction. Small 15, 1802228 (6p) (2019).

65. Xu, Z. et al. Effect of particle size on the activity and durability of the Pt/C electro catalyst for proton exchange membrane fuel cells. Appl. Catal. B Environ. 111-112, 264-270 (2012). 